\title{
A Structural Equation Model (SEM) for Pharmacist Competencies in Improving Quality of Life of Cancer Patients: Effect of Missing Values on the SEM
}

\author{
Rieko Takehira $^{1}$, Keiko Murakami ${ }^{2}$, Sirou Katayama ${ }^{2}$, Kenji Nishizawa ${ }^{3}$, Shigeo Yamamura ${ }^{1}$ \\ ${ }^{1}$ Faculty of Pharmaceutical Sciences, Josai International University, Chiba, Japan; ${ }^{2}$ Department of Pharmacy, Nippon Medical Uni- \\ versity Hospital, Tokyo, Japan; ${ }^{3}$ Department of Pharmacy, Omori Medical Center, Toho University, Tokyo, Japan. \\ Email: s_yama@jiu.ac.jp
}

Received April $1^{\text {st }}, 2011$; revised May 20 ${ }^{\text {th }}, 2011$; accepted June 22 ${ }^{\text {nd }}, 2011$.

\begin{abstract}
Objective: With the goal of improving health-related quality of life (HRQOL) in cancer patients, we previously reported a structural equation model (SEM) of subjected QOL and qualifications of pharmacists, based on a series of questionnaires completed by patients and pharmacists. However, several patients and pharmacists were excluded from the previous study because it was not always possible to obtain all the data intended for collection. In order to reveal the effect of missing data on the SEM, we established SEMs of HRQOL and the competency of pharmacists, using correlation matrices derived by two different statistical methods for handling missing data. Method: Fifteen cancer patients hospitalized for cancer and were receiving opioid analgesics for pain control, and eight pharmacists were enrolled in this study. Each subject was asked four times weekly to answer questions presented in a questionnaire. SEMs were explored using two correlation matrices derived with pair-wise deletion (PD matrix) and list-wise deletion (LD matrix). The final models were statistically evaluated with certain goodness-of-fit criteria. Results: Data were intended to be collected four times weekly for each patient, but there were some missing values. The same SEMs for HRQOL were optimized using both the LD and PD matrices. Although the path diagrams of the SEMs were not identical in the "competency of pharmacists," the two models suggested that a higher competency of a pharmacist lowered the "severity" of condition and increased the "comfort" of patients, resulting in an increase in the subjected QOL. Conclusions: In collecting data for clinical research, missing values are unavoidable. When the structure of the model was robust enough, the missing data had a minor effect on our SEM of QOL. In QOL research, the LD matrix as well as the PD matrix would be effective, provided the model is sufficiently robust.
\end{abstract}

Keywords: QOL, Cancer Patients, Structural Equation Model, Pharmacists, Missing Data

\section{Introduction}

Pharmaceutical care is defined as the responsible provision of drug therapy for achieving specific outcomes that improve a patient's quality of life (QOL) [1]. Typically, this improved QOL would be achieved in collaboration with other healthcare professionals. Intervention of pharmacists in patient care has been reported to improve patients' QOL in various diseases [2,3]. Gilbar reported that pharmacists play an important role in executing appropriate patient care in palliative care settings [4]. Cancer patients tend to experience increasing pain with pro- gressing stages of the cancer. Opioid preparations have been used to relieve the pain of cancer patients, according to the three-step analgesic ladder established by the WHO [5]. Relief from pain together with the management of adverse events with analgesics is essential in palliative care for cancer patients. By minimizing suffering with drug therapy, health-related QOL (HRQOL) of patients can be improved.

HRQOL of patients is a concept that consists of various elements, including emotional well-being (EWB), functional well-being (FWB), social well-being (SWB) and physical well-being (PWB), as suggested by Schip- 
per [6]. Religious spirituality should also be considered as an important element for terminally ill patients [7]. Accordingly, to enhance patient care, it is important to take into account the improvements in patients' HRQOL and evaluations of subjected QOL by patients. There are some tools to evaluate patients' QOL or HRQOL, including SF-36, FLIC, and FACT [8-11]. A support team assessment schedule (STAS) for evaluating the relevance between patients' objective outcome and support team assessment in a palliative care setting is also reported. $[12,13]$ Even with these tools, it is difficult to model the causal relationship between patients' HRQOL and the intervention of pharmacists in patients' care.

A SEM is known to model the direct and indirect relationships among the latent variables and is used to quantify explained and unexplained variance [14,15]. Because SEM can deal with the abstraction of psychological effects as latent variables, it has been applied to measure the HRQOL of patients in nursing care [16-18].

For various reasons related to patient care, investigators are not always successful in obtaining all the intended data in a clinical study. Although "missing data" can cause difficulties for statistical analysis, it is often unavoidable in a clinical setting. Shimozuma reported that issues based on missing data tend to increase when researching QOL in progressive cancer patients [19].

In our previous report, we established a SEM of subjected QOL in cancer patients, wherein we accounted for the competency of pharmacists using a matrix derived with list-wise deletion (LD matrix) [20]. However, in that report, only completed forms containing all the values collected from patients and pharmacists were used in the analysis, and all incomplete forms containing missing values were excluded. In QOL research in cancer patients, missing values were unavoidable in some cases, depending on the condition of the patient. In the present report, we established SEMs using the LD matrix and a matrix derived with pair-wise deletion (PD matrix), a method designed to handle missing data. We investigated the effect of missing data on the SEM of HRQOL of cancer patients and competency of pharmacists to improve patients' QOL.

\section{Methods}

\subsection{Participants}

Patients: Eighteen cancer patients hospitalized in Nippon Medical University Hospital (Sendagi, Tokyo Japan) were included in this study. All patients received opioid analgesics for pain control and appropriate care with a pain control team organized by physicians, pharmacists, and nurses in the hospital. Patients who started chemo-
Table 1. Questionnaire for patients.

\begin{tabular}{cc}
\hline No. & Questions \\
\hline 1 & Did you sleep well? \\
2 & Do you have uneasiness about your pain and/or nausea? \\
3 & Have you felt uneasy? \\
4 & Have you felt depressed? \\
5 & Have you felt unable to concentrate? \\
6 & Did you experience nausea? \\
7 & Did you vomit? \\
8 & Did you have constipation? \\
9 & Did you have diarrhea? \\
10 & Rate of your pain. \\
11 & Were you able to move freely without pain? \\
12 & Did you enjoy a book or radio or television program? \\
14 & Were you able to move freely to a rest room without assis- \\
15 & tance? \\
16 & Do you need more explanation about the effects and side ef- \\
17 & fects of the analgesics? \\
18 & Were you able to tell the pharmacist about your pain? \\
\hline
\end{tabular}

Q1 - Q5, EWB; Q6 - Q10, PWB; Q11 - Q13, FWB; Q14, SWB. Q15 - Q18 was to explore the relationship among patients and other health professionals. Answers were scores ranging in 1 to 5 except for Q10. Answers of Q10 were rated on a score ranging from 0 to 10. (Adapted from Yamamura, et al. (20))

therapy during this research or who did not complete the answer form due to severe illness were excluded. After obtaining their consent for participation, fifteen patients were enrolled in this study. A questionnaire designed to assess the HRQOL of patients consisted of four important domains: EWB, FWB, SWB, and PWB. The number of questions in the questionnaire was limited to eighteen in order to avoid unnecessary burden on the patients, as suggested by a local research committee.

Pharmacists: Eight pharmacists providing pharmaceutical care in a pain control team were included in this study. Many of them had experience in pain management as members of the pain control team in the hospital. Pharmacists scored patients' status simply, and not in a structured manner, by answering seven questions based on bedside interviews with the patients.

The study design and questionnaires were reviewed by a local research committee. The background of patients and questionnaires to patients and pharmacists are the same as described in our previous paper [20]. Questionnaires to patients and pharmacists are listed in Tables 1 and 2. Patients and pharmacists were asked four times weekly to answer the questionnaire.

\subsection{Covariance Matrix for SEM Analysis}

Although it was intended that sixty answers would be collected in the research, some answer forms from the patients or pharmacists were not completed, resulting in missing values. The number of completed paired (patient 
Table 2. Questionnaire for pharmacists.

\begin{tabular}{cc}
\hline No. & Questions \\
\hline 1 & Do you think that the patient understands the medication? \\
2 & $\begin{array}{c}\text { Do you think that the patient could communicate about his } \\
\text { or her pain with the physician? }\end{array}$ \\
3 & Do you think that the patient could communicate about his \\
4 & or her pain with the nurse? \\
5 & Do you think that you can grasp the patient's pain? \\
6 & How would you rate the overall QOL of the patient? \\
7 & How would you rate the pain scale of the patient?
\end{tabular}

Answers were noted as scores ranging from 1 to 5, except for Q6. Answers to Q6 were rated on a score ranging from 0 to 10 . (Adapted from Yamamura, et al. (20))

and pharmacist) answers was forty and the remaining twenty answers were removed to build the covariance coefficient matrix. This handling of missing data is known as list-wise deletion (a covariate matrix derived with list-wise deletion is called an LD matrix) [15]. An entire record is excluded from an analysis if a single value is missing. The other method for handing missing data is known as a pair-wise deletion. All answers are included and each covariance between variables is computed solely on the basis of available pairs of observations (a covariate matrix derived with pair-wise deletion is called a PD matrix). SEM using the PD matrix is considered suitable for confirmatory analysis and unsuitable for exploratory analysis.

\subsection{Structural Equation Modeling (SEM)}

SEM is a comprehensive statistical approach to test hypotheses about the relation among latent and/or observed variables. Possible models including latent and observed variables were built with AMOS 18J (SPSS Japan, Tokyo, Japan). We developed a possible model using the following criteria: 1) The model could be reasonably explained, and 2) The fitting between the model and the data could be evaluated statistically by certain goodnessof-fit (GOF) parameters: goodness-of-fit index (GFI) or adjusted goodness of fit index (AGFI) of 0.90 or greater, comparative goodness-of-fit index (CFI) of 0.90 or greater, and root-mean square error of the approximation (RMSEA) less than 0.05 [15]. Akaike's information criterion (AIC), a measure of GOF criteria adjusting for the number of estimated parameters, was also used to evaluate GOF. Owing to the use of different sample sizes for computing covariance terms in the model with the PD matrix, AIC would not be a good GOF criteria, but it was indicated for reference. Robustness of the model was investigated by a leave-one-out cross validation (LOOV). In the LOOV procedure, the model was established using covariance matrices derived from the data sets after removal of 1 observation, and this procedure was repeated

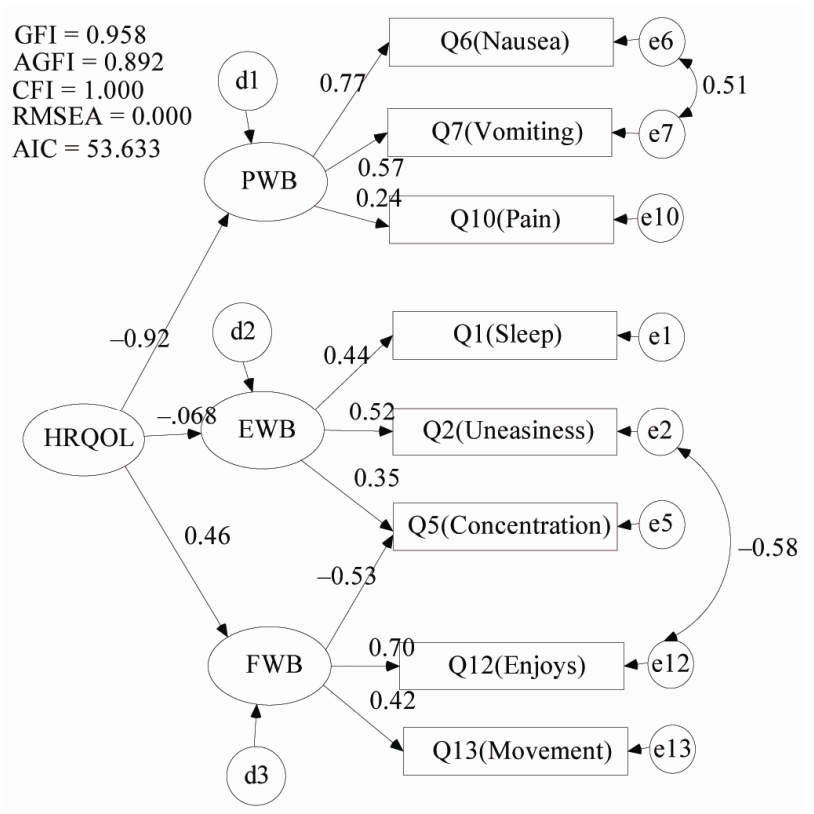

Figure 1. SEM for HRQOL of cancer patients optimized with the PD matrix EWB, emotional well-being; FWB, functional well-being and PWB, physical well-being.

for the number of data.

\section{Results and Discussion}

\subsection{SEMs for HRQOL}

Table 3 shows the covariance coefficients derived with PD and LD. The effect of missing data was minimal, depending on the handling of the missing data. Figure 1 shows a SEM for HRQOL established with a PD matrix with some statistical GOF parameters. The model showed the same path diagram as the model established with LD matrix described in our previous report[20], and fulfilled nearly all GOF criteria: GFI $=0.958$, AGFI $=0.892$, CFI $=1.000, \mathrm{RMSEA}=0.000$, and $\mathrm{AIC}=53.633$, indicating that that the model with the PD matrix can be considered a reasonable statistical model. The SEM for HRQOL of cancer patients was optimized to have three elements (PWB, EWB, and FWB) in four main elements of QOL reported in the literature $[6,20]$, regardless of the $L D$ and PD matrices. Table 4 summarizes the standardized estimates of regression weights among variables optimized with the LD and PD matrices. In the model with the PD matrix, mean and standard deviation (SD) evaluated by LOOV are also shown in Table 4 to reveal the robustness of the model. Some of the standardized regression weights between variables established with $\mathrm{LD}$ and $\mathrm{PD}$ matrices were close to each other, and others were slightly different, such as the weights between HRQOL to PWB, EWB and FWB. This can be considered as fol- 
A Structural Equation Model (SEM) for Pharmacist Competencies in Improving Quality of Life of Cancer Patients: Effect 229 of Missing Values on the SEM

Table 3. Covariance matrix for HRQOL derived with pairwise deletion and listwise deletion.

\begin{tabular}{|c|c|c|c|c|c|c|c|c|c|}
\hline & $\mathrm{Q} 1$ & Q2 & $\overline{\mathrm{Q} 5}$ & Q6 & $\overline{\mathrm{Q} 7}$ & Q10 & Q12 & Q13 & Q18 \\
\hline Q1 (Sleep) & 1.000 & & & & & & & & \\
\hline $\begin{array}{c}\text { Q2 } \\
\text { (Uneasiness) }\end{array}$ & $\begin{array}{c}0.203 \\
(0.165)\end{array}$ & 1.000 & & & & & & & \\
\hline Q5 (Concentration) & $\begin{array}{c}0.318 \\
(0.294)\end{array}$ & $\begin{array}{c}0.237 \\
(0.234)\end{array}$ & 1.000 & & & & & & \\
\hline Q6 (Nausea) & $\begin{array}{c}0.173 \\
(0.158)\end{array}$ & $\begin{array}{c}0.355 \\
(0.340)\end{array}$ & $\begin{array}{c}0.298 \\
(0.312)\end{array}$ & 1.000 & & & & & \\
\hline Q7 (Vomiting) & $\begin{array}{c}0.052 \\
(0.006)\end{array}$ & $\begin{array}{c}0.273 \\
(0.290)\end{array}$ & $\begin{array}{c}0.205 \\
(0.160)\end{array}$ & $\begin{array}{c}0.706 \\
(0.665)\end{array}$ & 1.000 & & & & \\
\hline Q10 (Pain) & $\begin{array}{c}0.034 \\
(0.042)\end{array}$ & $\begin{array}{c}0.004 \\
(-0.019)\end{array}$ & $\begin{array}{c}0.156 \\
(0.158)\end{array}$ & $\begin{array}{c}0.184 \\
(0.188)\end{array}$ & $\begin{array}{c}0.149 \\
(0.178)\end{array}$ & 1.000 & & & \\
\hline $\begin{array}{c}\text { Q12 (Enjoys } \\
\text { books/radio/TV) }\end{array}$ & $\begin{array}{l}-0.148 \\
(-0.175)\end{array}$ & $\begin{array}{l}-0.450 \\
(-0.476)\end{array}$ & $\begin{array}{l}-0.446 \\
(-0.451)\end{array}$ & $\begin{array}{c}-0.292 \\
(-0.343)\end{array}$ & $\begin{array}{c}-0.288 \\
(-0.359)\end{array}$ & $\begin{array}{c}-0.079 \\
(-0.087)\end{array}$ & 1.000 & & \\
\hline Q13 (Movement) & $\begin{array}{c}0.009 \\
(0.007)\end{array}$ & $\begin{array}{c}0.087 \\
(0.012)\end{array}$ & $\begin{array}{c}-0.279 \\
(-0.259)\end{array}$ & $\begin{array}{l}-0.143 \\
(-0.251)\end{array}$ & $\begin{array}{l}-0.255 \\
(-0.273)\end{array}$ & $\begin{array}{c}0.075 \\
(-0.60)\end{array}$ & $\begin{array}{c}0.226 \\
(0.213)\end{array}$ & 1.000 & \\
\hline Q18 (QOL) & $\begin{array}{l}-0.051 \\
(-0.032)\end{array}$ & $\begin{array}{l}-0.167 \\
(-0.171)\end{array}$ & $\begin{array}{l}-0.191 \\
(-0.228)\end{array}$ & $\begin{array}{c}0.000 \\
(-0.010)\end{array}$ & $\begin{array}{l}-0.066 \\
(-0.068)\end{array}$ & $\begin{array}{c}-0.095 \\
(-0.054)\end{array}$ & $\begin{array}{l}0.268 \\
(0.217\end{array}$ & $\begin{array}{l}-0.046 \\
(-0.081)\end{array}$ & 1.000 \\
\hline $\mathrm{SD}^{*} 1$ & $\begin{array}{c}0.976 \\
(0.975) \\
\end{array}$ & $\begin{array}{c}1.380 \\
(1.377) \\
\end{array}$ & $\begin{array}{c}1.277 \\
(1.310) \\
\end{array}$ & $\begin{array}{c}1.580 \\
(1.509) \\
\end{array}$ & $\begin{array}{c}1.203 \\
(1.148) \\
\end{array}$ & $\begin{array}{c}1.874 \\
(1.757) \\
\end{array}$ & $\begin{array}{c}1.337 \\
(1.377)\end{array}$ & $\begin{array}{c}1.900 \\
(1.945) \\
\end{array}$ & $\begin{array}{c}0.791 \\
(0.816) \\
\end{array}$ \\
\hline
\end{tabular}

* 1 SD is the standard deviation of answers to each question. Please refer to questions in Table 1.

Table 4. Standardized estimates of SEM for HRQOL with PD and LD matrices.

\begin{tabular}{|c|c|c|c|c|c|c|}
\hline \multirow{2}{*}{\multicolumn{3}{|c|}{ Standardized regression weights }} & \multicolumn{3}{|c|}{$\mathrm{PD}$} & \multirow{4}{*}{$\begin{array}{c}\text { LD } \\
\text { Estimate } \\
-0.808\end{array}$} \\
\hline & & & \multirow{3}{*}{$\begin{array}{c}\text { Estimate } \\
-0.916\end{array}$} & \multicolumn{2}{|c|}{ Cross-validation } & \\
\hline & & & & Mean & SD & \\
\hline PWB & $<---$ & HRQOL & & -0.896 & 0.061 & \\
\hline EWB & $<---$ & HRQOL & -0.684 & -0.685 & 0.040 & -0.791 \\
\hline FWB & $<---$ & HRQOL & 0.459 & 0.462 & 0.059 & 0.686 \\
\hline Q6 (Nausea) & $<---$ & PWB & 0.773 & 0.782 & 0.066 & 0.838 \\
\hline Q7 (Vomiting) & $<---$ & PWB & 0.566 & 0.568 & 0.059 & 0.630 \\
\hline Q10 (Pain) & $<---$ & PWB & 0.239 & 0.237 & 0.018 & 0.231 \\
\hline Q1 (Sleep) & $<---$ & EWB & 0.436 & 0.441 & 0.034 & 0.361 \\
\hline Q2 (Uneasiness) & $<---$ & EWB & 0.519 & 0.516 & 0.049 & 0.523 \\
\hline Q5 (Concentration) & $<---$ & EWB & 0.355 & 0.362 & 0.048 & 0.209 \\
\hline Q5 (Concentration) & $<---$ & FWB & -0.532 & -0.530 & 0.034 & -0.520 \\
\hline Q12 (Enjoys book/radio/TV) & $<---$ & FWB & 0.703 & 0.703 & 0.030 & 0.712 \\
\hline Q13 (Movement) & $<---$ & FWB & 0.420 & 0.419 & 0.022 & 0.385 \\
\hline
\end{tabular}

PD: Pair-wise deletion, LD: List-wise deletion. Estimates were calculated from the optimized SEM. The values of cross-validation were obtained by the leaveone-out cross-validation.

lows: the data from the patients who did not answer the questions due to the severity of illness were not included in the LD matrix. The relationship between HRQOL to PWB consisting of the scores of nausea, vomiting, and pain, would be strong in the PD matrix. Therefore, the regression weight from HRQOL to PWB in the LD matrix would become larger than that in the PD matrix. According to be strength of the relation between HRQOL to PWB, regression weights between HRQOL to EWB and QOL to FWB would be relatively smaller. The SD of estimates evaluated by LOOV was reasonably narrow, suggesting that the optimized SEM was robust and not affected strongly by outlier(s).

Figure 2 shows the model indicating the relationship between the HRQOL modeled with PD matrix and subjected QOL (Q18 QOL in Figure 2) answered by the patients. The GOF criteria of the model were calculated to be $\mathrm{GFI}=0.942, \mathrm{AGFI}=0.876, \mathrm{CFI}=1.000$, RMSEA $=0.000$, and AIC $=63.524$. The correlation coefficient between HRQOL and subjected QOL was poor, calculated to be 0.22 . The correlation coefficient in the model with LD matrix was also poor, calculated to be 0.23 [20]. These results suggest that a meaningful part of subjected QOL in patients is influenced by other elements not included in the model. Table 5 summarizes the standardized regression weights between variables. Similar to Table 4, the regression weight from HRQOL to PWB in the model with PD matrix was larger than that with LD 
Table 5. Standardized estimates of SEM for Competencies optimized with PD and LD matrices.

\begin{tabular}{|c|c|c|c|c|c|c|}
\hline \multirow{2}{*}{\multicolumn{3}{|c|}{ Standardized regression weights }} & \multicolumn{3}{|c|}{ PD } & \multirow{3}{*}{$\begin{array}{c}\begin{array}{c}\mathrm{LD} \\
\text { Estimate }\end{array} \\
-0.727\end{array}$} \\
\hline & & & \multirow{2}{*}{$\begin{array}{c}\text { Estimate } \\
-0.799\end{array}$} & \multicolumn{2}{|c|}{ Cross-validation } & \\
\hline PWB & $<---$ & HRQOL & & -0.794 & 0.062 & \\
\hline EWB & $<---$ & HRQOL & -0.772 & -0.767 & 0.049 & -0.845 \\
\hline FWB & $<---$ & HRQOL & 0.589 & 0.591 & 0.068 & 0.799 \\
\hline Q6 (Nausea) & $<---$ & PWB & 0.686 & 0.694 & 0.074 & 0.761 \\
\hline Q7 (Vomiting) & $<---$ & PWB & 0.532 & 0.539 & 0.050 & 0.600 \\
\hline Q10 (Pain) & $<---$ & PWB & 0.270 & 0.269 & 0.039 & 0.255 \\
\hline Q1 (Sleep) & $<---$ & EWB & 0.459 & 0.458 & 0.029 & 0.380 \\
\hline Q2 (Uneasiness) & $<---$ & EWB & 0.475 & 0.478 & 0.041 & 0.479 \\
\hline Q5 (Concentration) & $<---$ & EWB & 0.389 & 0.388 & 0.039 & 0.274 \\
\hline Q5 (Concentration) & $<---$ & FWB & -0.483 & -0.481 & 0.041 & -0.471 \\
\hline Q12 (Enjoys book/radio/TV) & $<---$ & FWB & 0.708 & 0.711 & 0.027 & 0.714 \\
\hline Q13 (Movement) & $<---$ & FWB & 0.406 & 0.405 & 0.025 & 0.360 \\
\hline
\end{tabular}

PD: Pair-wise deletion, LD: List-wise deletion. Estimates were calculated from the optimized SEM. The values of cross-validation were obtained by the leaveone-out cross-validation.

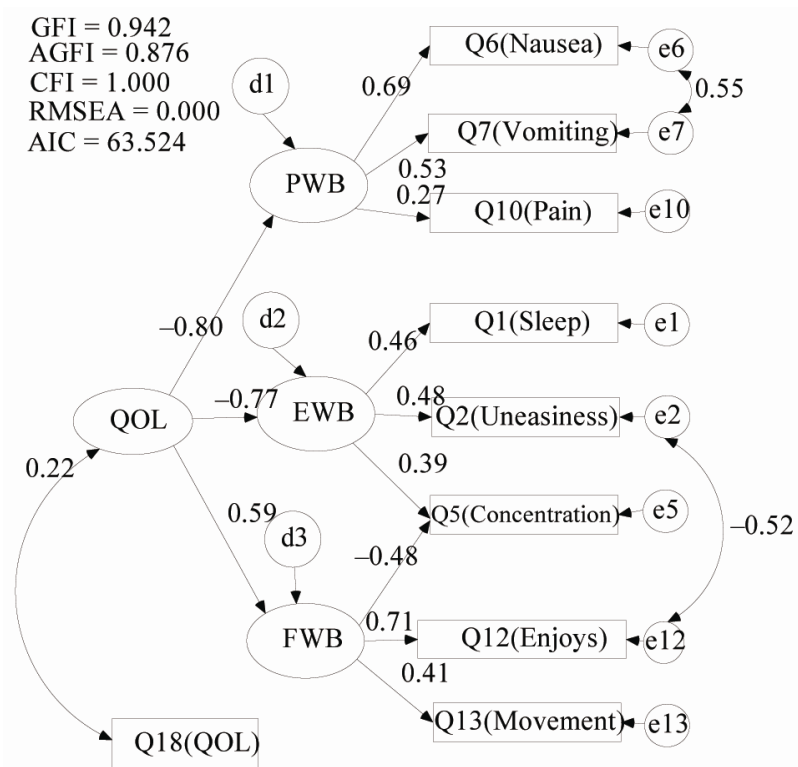

Figure 2. SEM of correlation between HRQOL and subjected QOL in patients optimized with the PD matrix EWB, emotional well-being; FWB, functional well-being and PWB, physical well-being.

matrix, resulting in similar effects described before. The SD of the estimates evaluated by LOOV was reasonably narrow suggesting that the optimized SEM was not affected strongly by outlier(s). These results indicate that the HRQOL model with a path diagram described in Figures 1 and $\mathbf{2}$ would be robust enough against missing values and outliers. The SEM analysis with both LD and PD matrices would have advantages with regard to the effect of missing data.

\subsection{SEM of Pharmacist Competency in Improving QOL of Patients}

We previously reported the SEM for the competency of pharmacists to improve subjected QOL of patients [20]. The model consisted of four latent variables, expressing "ability of pharmacists," "skill of assessment" of pain level in patients, "severity" of side effect and "comfort" level, respectively. The model suggested that the competency of pharmacists can improve subjected QOL in cancer patients. Table 6 shows the covariance coefficients used for SEM analysis of competency of pharmacists to improve patients' subjected QOL calculated with the PD and LD. Some coefficients were found to be affected by missing data, in contrast to the model of HRQOL. To establish the SEM, we introduced another parameter, i.e., the absolute value of difference of pain scores answered by patients and evaluated by pharmacists. This variable would indicate the pharmacists' competency to understand the patients' condition. A smaller value for this variable would indicate the pharmacist's ability to evaluate the patients' pain more accurately. The optimized model established with the PD matrix is shown in Figure 3, and GOF criteria of the model were almost satisfactory: $\mathrm{GFI}=0.932, \mathrm{AGFI}=0.856, \mathrm{CFI}=$ 1.000, RMSEA $=0.000$ and $\mathrm{AIC}=63.124$.

The final model consists of three latent variables, expressing "competency of pharmacists," "severity” of side effect, and "comfort" level. From the magnitude of estimates of standardized weight between variables, the model can be explained as follows: when pharmacists are highly competency to assess patients' pain level based on experiences from previous association with a pain control team, they can work to restrain unpleasant symptoms 
A Structural Equation Model (SEM) for Pharmacist Competencies in Improving Quality of Life of Cancer Patients: Effect 231 of Missing Values on the SEM

Table 6. Covariance matrix for competency of pharmacists derived by Pair-wise deletion and List-wise deletion.

\begin{tabular}{|c|c|c|c|c|c|c|c|c|}
\hline & Pt-Q2 & Pt-Q5 & Pt-Q8 & Pt-Q10 & Pt-Q18 & Ph-Q4 & Ph-Q7 & Difference \\
\hline Pt-Q2 (Uneasiness) & 1.000 & & & & & & & \\
\hline Pt-Q5 (Concentration) & $\begin{array}{c}0.237 \\
(0.234)\end{array}$ & 1.000 & & & & & & \\
\hline Pt-Q8 (Constipation) & $\begin{array}{c}0.299 \\
(0.222)\end{array}$ & $\begin{array}{c}0.137 \\
(0.203)\end{array}$ & 1.000 & & & & & \\
\hline Pt-Q10 (Pain) & $\begin{array}{c}0.184 \\
(0.205)\end{array}$ & $\begin{array}{c}0.099 \\
(0.141)\end{array}$ & $\begin{array}{c}0.457 \\
(0.568)\end{array}$ & 1.000 & & & & \\
\hline Pt-Q18 (QOL) & $\begin{array}{c}-0.167 \\
(-0.171)\end{array}$ & $\begin{array}{c}-0.191 \\
(-0.228)\end{array}$ & $\begin{array}{c}-0.256 \\
(-0.354)\end{array}$ & $\begin{array}{c}-0.173 \\
(-0.137)\end{array}$ & 1.000 & & & \\
\hline Ph-Q4 (Grasp pain) & $\begin{array}{c}0.052 \\
(0.086)\end{array}$ & $\begin{array}{c}0.047 \\
(0.221)\end{array}$ & $\begin{array}{c}-0.024 \\
(-0.087)\end{array}$ & $\begin{array}{c}0.020 \\
(-0.060)\end{array}$ & $\begin{array}{c}-0.158 \\
(-0.090)\end{array}$ & 1.000 & & \\
\hline Ph-Q7 (Experience) & $\begin{array}{c}0.027 \\
(0.019)\end{array}$ & $\begin{array}{l}-0.001 \\
(-0.028)\end{array}$ & $\begin{array}{c}-0.101 \\
(-0.158)\end{array}$ & $\begin{array}{l}-0.049 \\
(-0.006)\end{array}$ & $\begin{array}{c}0.215 \\
(0.233)\end{array}$ & $\begin{array}{c}-0.212 \\
(-0.291)\end{array}$ & 1.000 & \\
\hline $\begin{array}{l}\text { Difference } \\
\text { Pain score *1 }\end{array}$ & $\begin{array}{c}-0.164 \\
(-0.116)\end{array}$ & $\begin{array}{c}-0.085 \\
(-0.104)\end{array}$ & $\begin{array}{l}0.157 \\
0.183\end{array}$ & $\begin{array}{c}0.305 \\
(0.294)\end{array}$ & $\begin{array}{c}0.114 \\
(0.202)\end{array}$ & $\begin{array}{c}-0.011 \\
(-0.107)\end{array}$ & $\begin{array}{c}0.220 \\
(0.310)\end{array}$ & 1.000 \\
\hline $\mathrm{SD}^{*} 2$ & $\begin{array}{c}1.380 \\
(1.377)\end{array}$ & $\begin{array}{l}1.277 \\
1.310\end{array}$ & $\begin{array}{l}1.645 \\
1.641\end{array}$ & $\begin{array}{l}1.895 \\
1.836\end{array}$ & $\begin{array}{c}0.791 \\
(0.816)\end{array}$ & $\begin{array}{l}0.592 \\
0.526\end{array}$ & $\begin{array}{c}0.298 \\
(0.607)\end{array}$ & $\begin{array}{c}1.163 \\
(1.091)\end{array}$ \\
\hline
\end{tabular}

$\mathrm{Pt}$ and $\mathrm{Ph}$ indicate the questions for patients and pharmacist, respectively. Upper and lower values were obtained with pairwise deletion and listwise deletion, respectively. ${ }^{*} 1$ Difference of pain score between by Pt and Ph. ${ }^{*} 2$ SD is the standard deviation of the answer to each question. Please refer to questions in Tables 1 and 2.

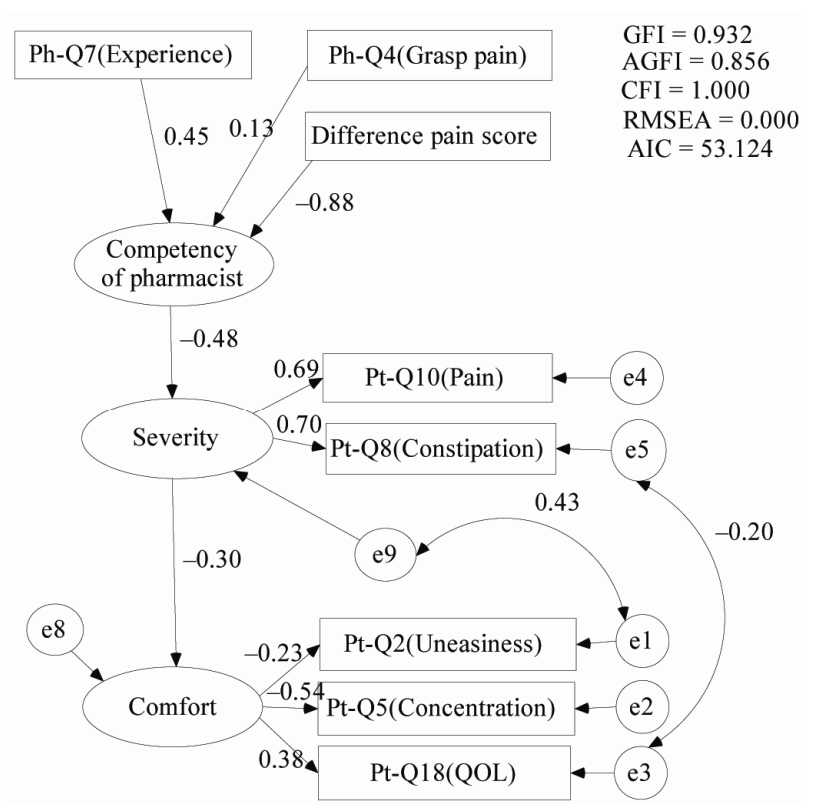

Figure 3. SEM of competency of pharmacists to improve subjected QOL of cancer patients optimized with the PD matrix.

such as pain and constipation. If "severity" of side effects can be reduced by competency of pharmacists, "comfort" level of patients would be increased with decreasing uneasiness and increasing of subjected QOL. Because the covariate coefficients with the PD matrix were a little different from those with the LD matrix, the optimized path diagrams were slightly different from each other. However, the most important factor of competency of pharmacists in improving subjected QOL of patients was to assess the pain level of patients in both models. The models suggest that pharmacists with prior experience in a pain control team and are competent to assess patients' pain level can restrain the unpleasant symptoms of patients. As a result, subjected QOL in patients will improve.

\section{Conclusions}

The models for HRQOL of cancer patients and for pharmacists' competency to improve the subjected QOL could be established using the SEM. If there was little effect of missing values and outliers on the SEM, similar SEMs were optimized with both the LD and the PD matrices. When using the PD matrix, AIC was not a good criterion because the sample sizes for computing covariance terms were different with each other. Therefore, SEM with the PD matrix should be used for confirmatory analysis after the model has been fixed using the LD matrix. In this study, we found that if the model is sufficiently robust and if there is little effect of missing values and outliers, the PD matrix could be also effective to establish the models for HRQOL and competency of pharmacists by SEM. The two models established with LD and PD matrices strongly suggest that competency of pharmacists can improve subjected QOL of patients.

\section{References}

[1] C. D. Hepler and L. M. Strand, "Opportunities and Responsibilities in Pharmaceutical Care,” American Journal of Hospital Pharmacy, Vol. 47, No. 3, 1990, pp. 533-543.

[2] B. J. Bereznicki, G. M. Peterson, S. L. Jackson, H. Walters, K. Fitzmaurice and P. Gee, "Pharmacist-Initiated General Practitioner Referral of Patients with Suboptimal Asthma Management," Pharmacy World and Science, Vol. 30, No. 6, 2008, pp. 869-875. 


\section{$\underline{\text { doi:10.1007/s11096-008-9242-3 }}$}

[3] M. Kamatari, S. Koto, N. Ozawa, C. Urao, Y. Suzuki, E. Akasaka, K. Yanagimoto and K. Sakota, "Factors Affecting Long-Term Compliance of Osteoporotic Patients with Bisphosphonate Treatment and QOL Assessment in Actual Practice: Alendronate and Risedronate,” Journal of Bone and Mineral Metabolism, Vol. 25, No. 5, 2007, pp. 302-309.doi:10.1007/s11096-008-9242-3

[4] P. Gilbar and K. Stefaniuk, "The Role of the Pharmacist in Palliative Care: Results of a Survey Conducted in Australia and Canada," Indian Journal of Palliative Care, Vol. 18, No. 4, 2002, pp. 287-292.

[5] World Health Organization, "Cancer Pain Relief: With a Guide to Opioid Availability,” 2 Edition, World Health Organization, New delhi, 1996.

[6] H. Schipper, "Guidelines and Caveats for Quality of Life Measurement in Clinical Practice and Research," Oncology, Vol. 4, No. 5, 1990, pp. 51-57.

[7] S. Kaasa and J. H. Loge, "Quality of Life in Palliative Care: Principles and Practice,” Palliative Medicine, Vol. 17, No. 1, 2003, pp. 11-20. doi:10.1007/s11096-008-9242-3

[8] J. E. Ware Jr and C. D. Sherbourne, "The MOS 36-Item Short-Form Health Survey (SF-36). I. Conceptual Frame Work and Item Selection,” Medical Care, Vol. 30, No. 6, 1992, pp. 473-483. doi:10.1097/00005650-199206000-00002

[9] H. Schipper, J. Clinch, A. McMurray and M. Levitt, "Measuring the Quality of Life of Cancer Patients: The Functional Living Index-Cancer: Development and Validation," Journal of Clinical Oncology, Vol. 2, No. 5, 1984, pp. 472-483.

[10] D. F. Cella, D. S. Tulsky, G. Gray, B. Sarafian, E. Linn, A. Bonomi, M. Silberman, S. B. Yellen, P. Winicour, J. Brannon, et al., "The Functional Assessment of Cancer Therapy Scale: Development and Validation of the General Measure,” Journal of Clinical Oncology, Vol. 11, No. 3, 1993, pp. 570-579.

[11] W. L. Ward, E. A. Hahn, F. Mo, L. Hernandez, D. S. Tulsky and D. Cella, "Reliability and Validity of the Functional Assessment of Cancer Therapy-Colorectal (FACT-C) Quality of Life Instrument," Quality of Life Research, Vol. 8, No. 3, 1999, pp. 181-195.

\section{doi:10.1023/A:1008821826499}

[12] M. G. Carson, M. I. Fitch and M. L. Vachon, "Measuring Patient Outcomes in Palliative Care: A Reliability and Validity Study of the Support Team Assessment Schedule," Palliative Medicine, Vol. 14, No. 1, 2000, pp. 2536. doi:10.1017/S1478951504040507

[13] M. Miyashita, K. Matoba, T. Sasahara, Y. Kizawa, M. Maruguchi, M. Abe, M. Kawa and Y. Shima, "Reliability and Validity of the Japanese Version of the Support Team Assessment Schedule (STAS-J),” Palliative \& Supportive Care, Vol. 2, No. 4, 2004, pp. 379-385. doi:10.1017/S1478951504040507

[14] R. H. Hoyle (Ed), "Structural Equation Modeling: Concepts, Issues, and Applications," Sage Publications, Thousand Oaks, California, 1995.

[15] B. M. Byrne, "Structural Equation Modeling with Amos: Basic Concepts, Applications, and Programming (Multivariate Applications Series)," Lawrence Erlbaum Assoc Inc. Publishers, Mahwah, New Jersey, 2001.

[16] C. H. Yeh, "Health-Related Quality of Life in Pediatric Patients with Cancer. A Structural Equation Approach with the Roy Adaptation Model," Cancer Nursing, Vol. 25, No. 1, 2002, pp. 74-80. doi:10.1097/00002820-200202000-00013

[17] K. H. Sousa and F. F. Dhen, "A Theoretical Approach to Measuring Quality of Life,” Journal of Nursing Measurement, Vol. 10, No. 1, 2002, pp. 47-58. doi:10.1891/jnum.10.1.47.52545

[18] L. B. Meuleners, A. H. Lee, C. W. Binns and A. Lower, "Quality of Life for Adolescents: Assessing Measurement Properties Using Structural Equation Modeling,” Quality of Life Research, Vol. 12, No. 3, 2003, pp. 283-290. doi:10.1023/A:1023221913292

[19] K. Shimozuma, “Quality of Life Assessment,” Breast Cancer, Vol. 9, No. 2, 2002, pp. 100-106. doi:10.1007/BF02967573

[20] S. Yamamura, R. Takehira. K. Kawada, S. Katayama, K. Nishizawa, M. Hirano and Y. Momose, "Structural Equation Modeling of Qualification of Pharmacists to Improve Subjected Quality of Life in Cancer Patients," Journal of Pharmacy \& Pharmaceutical Sciences, Vol. 8, 2005, pp. 544-551. 